\title{
Ontology-Driven Business Process Design
}

\author{
Carla Marques Pereira ${ }^{2,3}$, Artur Caetano ${ }^{1,3}$, and Pedro Sousa ${ }^{1,2}$ \\ ${ }^{1}$ Department of Computer Science and Engineering, Instituto Superior Técnico, \\ Technical University of Lisbon, Av. Rovisco Pais, 1049-001 Lisboa, Portugal \\ ${ }^{2}$ Link, Av. Duque de Ávila, 23, 1000-138 Lisboa, Portugal \\ ${ }^{3}$ INESC ID \& INESC INOV, Rua Alves Redol 9, 1000-029 Lisboa, Portugal \\ carla.pereira@link.pt, \{artur.caetano, pedro.sousa\}@ist.utl.pt
}

\begin{abstract}
Rapid business change demands the ability to adapt, rearrange and reinvent business processes while keeping the alignment with supporting information systems. However, such tasks require a business process to be consistently specified and modelled. To address this issue, this paper describes an organizational taxonomy that defines a controlled vocabulary to design business processes using the concepts of information entity, business process, organizational unit, actor, business schedule and business goal.
\end{abstract}

Keywords: organizational taxonomy, ontology, business process design, conceptual modelling.

\section{Introduction}

Business process management plays a central role at operational, organizational and technological levels [1-3]. Business process modelling produces abstract descriptions of business processes that are a central asset to the organization as they enable its specification, documentation, analysis and engineering through multiple paradigms, languages and techniques [3-7]. However, process modelling languages are often criticised due to the lack of mechanisms to deal with domain changes and with the integration of requirements from multiple stakeholders $[8,9]$.

The goal of this paper is to define a shared language that enables specifying business processes while serving as a communication, analysis and discussion platform to its stakeholders. Such goal attempts to minimize having multiple inconsistent specifications of the same business process for different stakeholder subgroups.

We argue that such inconsistent specifications stem from two main causes. The first one is that the different stakeholders of the same process tend to belong to different organizational areas as a business process also tends to crosscut intra- or even inter-organizational boundaries. Hence, stakeholders have contrasting concerns and thus focus on different perspectives of a process such as performance, auditing, information systems and compliance. This problem also arises during the design of architectural descriptions and can be addressed by having multiple views over the same conceptual domain $[10,11]$. The second cause is that the specification of a business process is intrinsically tied to its design team. Therefore, the process design is 
influenced not only by the organizational factors that do specify the process but also by the team's knowledge and background. The outcome of such observation is that two different design teams modelling the same process tend to obtain different specifications. Moreover, the formally defined modelling concepts used in widely used business processes modelling languages such as BPMN and EPC depend on natural language to specify concepts such as activities, events and information. Therefore, if the different modelling teams do not share a common vocabulary to describe a business process, the task of assessing whether two process models are actually equivalent is complex.

This paper describes a controlled vocabulary that encompasses a set of core constructs to define a business process. This vocabulary is independent of the actual process modelling language and intends to facilitate the analysis and communication of a process, especially when multiple design teams or multiple stakeholders are involved.

The remainder of this paper is structured as follows. The next section reviews related work. Sections 3 introduce the concepts, ontology and taxonomy to support business design. Finally, section 4 summarizes the project.

\section{Related Work}

Organizations require different perspectives for modelling business processes, such as modelling for compliance, documentation, process redesign or execution. Regardless of the goal, the output should be a process representation that enables its analysis, sharing and communication. Reference models and taxonomies can be used to increase the consistency of process modelling through the systematic reuse of proven and best practices across process design projects $[12,13]$. Reference models, such as the Supply Chain Operations Reference (SCOR), capture knowledge about common activities, information artefacts and flows encountered in specific application domains. However, their do not go beyond pre-defined repositories of process models and provide little or no guidance to support the adaptation of these models to specific needs or different application contexts. Moreover, there is a lack of notations and methods to model reference processes and to enable their systematic reuse of reference process models in business process management projects.

Techniques such as Petri nets [14], flowcharts [15], state charts [16], EPC [17], UML Activity Diagrams [18] and BPMN [19] are valuable for specifying the controlflow associated with a business process. Entity-relationship diagrams [20] and data flow diagrams [21] are useful to capture the data handled by a process. Other approaches such as Speech Act Theory [22] and the Language/Action Perspective [23] model the interaction between actors and systems and how they do so.

However, most of these techniques are only able to address a single aspect of the domain, with a strong emphasis on control or data flow modelling. Therefore, supplementary modelling mechanisms are required to provide a comprehensive description of the process. This also implies that these different mechanisms need to be tightly integrated so that the resulting models are consistent and traceable. Since assessing the coherence and equivalence of the different representations of the same process is complex, organizations are compelled to design and maintain various representations of the same domain. This 
makes analysing and communicating the processes complex and also hinders the design of the information systems that support these business processes because there is no single source of knowledge. For instance, an EPC model specifies resources and objects which are required for handling specific activities at one process level but defines no criteria on how to decompose those elements. And BPMN and EPC express activities, information and events in natural language which tend lead to further modelling ambiguity if no proper shared vocabulary is defined.

The next sections introduce the concepts required to define such a shared vocabulary regardless of the process modelling language.

\section{Core Concepts}

The purpose of business process design is the construction of concise and unambiguous models of a business or a business area in terms of the activities that take place in the organization. The fundamental assumption behind this project is that a business process can be represented through the identification of the concepts that are associated to the following six dimensions: what, where, who, when, why and how, i.e. the classic 5W1H dimensions [24, 25].

A business process can be functionally decomposed into a set of individual tasks. While we refer to a business process as a set of activities, both concepts are actually interchangeable. However, the resulting decomposition structure needs to be formalized in order to avoid unambiguity. We use Krogstie \& Sølvberg's definition of hierarchy to model the functional decomposition of a process into finer grained elements [26]. This definition states that $\mathbf{H}$ is an hierarchy iff it is an ordered triple $\mathbf{H}=\langle\mathbf{S}, \mathbf{b}, \mathbf{D}\rangle$ where $\mathbf{S}$ is a nonempty set, $\mathbf{b}$ a distinguished element of $\mathbf{S}$ and $\mathbf{D}$ a binary relation over $\mathbf{S}$ such that:

1. $\mathbf{S}$ has a single beginner, $\mathbf{b}$. (H has one and only one supreme commander)

2. $\mathbf{b}$ stands in some power of $\mathbf{D}$ to every other member of $\mathbf{S}$. (That is, no matter how low in the hierarchy an element of S may stand, it is still under the command of the beginner)

3. For any given element $\mathbf{y}$ of $\mathbf{S}$ except $\mathbf{b}$, there is exactly one other element $\mathbf{x}$ of $\mathbf{S}$ such that $\mathbf{D}_{\mathbf{x y}}$. (i.e. every member has a single direct boss.)

4. D is transitive and anti-symmetric.

Therefore, we assume the resulting process tree is strict hierarchal graph i.e. a digraph whose underlying graph is a tree, and for which there is one specific vertex from which all other vertices can be reached.

The relationships between the concepts can take the form of classification, aggregation and generalization:

- Classification ("is member of"). Abstracts a concept as a class of objects characterized by common properties.

- Aggregation ("is part of"). Defines a new class from a set of classes that represent its component parts, i.e., thinking of concepts as wholes, not just a collection of their attributes/components. 
- Generalization ("is a"). Defines a subset relationship between the elements of two or more classes, i.e., abstracting commonalities of several classes into a superclass.

\section{The Organizational Taxonomy}

An organizational taxonomy defines a controlled vocabulary which aims to be understandable to all the process stakeholders. It is a collection of terms organized as an hierarchical structure as described in the previous section. Each term is in one or more parent-child relationships to other terms in the taxonomy. The organizational taxonomy here described represents the hierarchical classification of the concepts used to represent business processes. A taxonomy helps to structure, classify, model and represent the concepts and relationships pertaining to business process design while enabling a community to come to agreement and to commit to use the same terms in the same way.

We define a business process (v. Figure 1) as a set of connected activities (how) which consumes and produces tangible or intangible artefacts (what), is performed by people or systems (who), contributes to achieving goals (why), takes place in a specific location (where) and during a specific period of time (when).

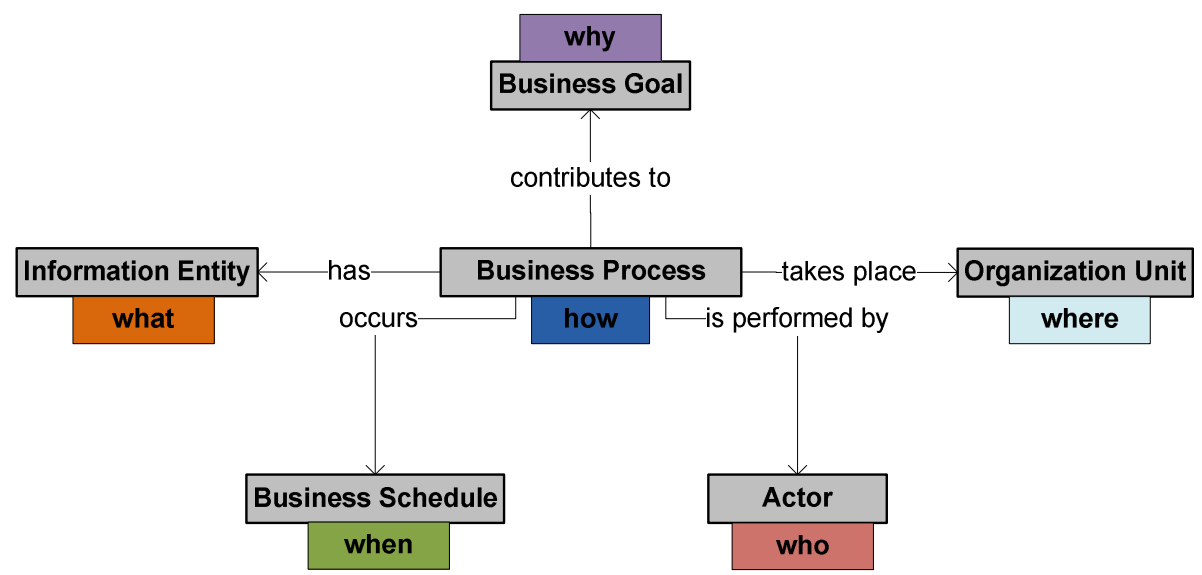

Fig. 1. The six core concepts of a business process and the corresponding six classification dimensions (why, what, where, when, who and how)

For each of these concepts we create a taxonomy based on the categorization of each concept instantiation in the classification structure. The definition of the classification structure is directly dependent of the way how the organization conducts its business and it can be different from organization to organization. For this reason it is necessary to define the ontology that should be applied for each concept and this must be recognized for all the stakeholders. We consider an ontology to be a formal explicit description of the concepts within a domain of discourse, the properties of each concept and the relationships between the concepts. The following subsections describe the ontologies for each of the concepts depicted in Figure 1, namely BUSINESS PROCESS, INFORMATION ENTITY, ORGANIZATIONAL UNIT, ACTOR, BUSINESS SCHEDULE and BUSINESS GOAL. 


\subsection{Business Process}

A BUSINESS PROCESS is a set of connected activities that consumes and produces tangible or intangible artefacts, is performed by people or systems, contributes to achieving goals, takes place in a specific location and during a specific period of time. A business process can be functionally decomposed as a set of individual tasks. Thus, a business process:

- Has one or more INFORMATION ENTITIES as input/output.

- Takes place in one or more ORGANIZATION UNITS.

- Is performed by one or more ACTORS.

- Occurs in a specific BUSINESS SCHEDULE.

- Contributes to one or more BUSINESS GOALS.

Abusiness process can be classified as:

- MACRO-PROCESS. A large-scale business PROCESS that is initiated by a customer request, or by the decision of the company to enter a new line of business, and results in the delivery of a process or service to a customer, i.e., purchase, manufacturing, logistics, customer service, marketing, sales, etc.

- Process. At its most generic, any set of ACTIVITIES performed by a business that is initiated by an event, transforms information, materials or business commitments, and produces an output. Process can be decomposed indefinitely.

- ACTIVITy. The leaves of the process tree are activities. So, an ACTIVITY is a PROCESS that cannot be further decomposed.

The following diagram depicts an ontology for a business process according to the concepts of business process, macro-process, process and activity.

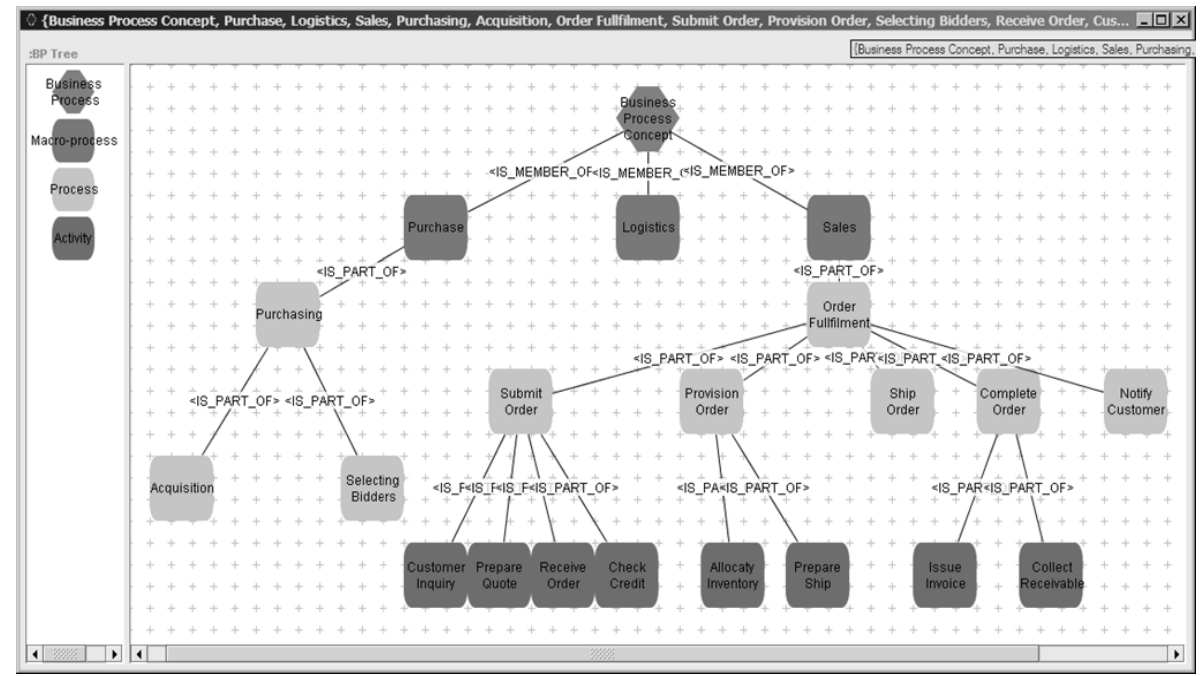

Fig. 2. Application of the ontology to a business process 


\subsection{Information Entity}

An entity is any person, place, concept, thing, or event that has meaning in the context of the business, and about which data may be stored [27]. INFORMATION ENTITIES are composed by several attributes and can have relationships with other entities. An entity can be classified as:

- ThING. It is an information "bag" that represents the many different types of electronic or physical artefacts that are important to the business, such as documents, products, resources, etc.

- Data EnTity. Is something that has some meaning in the context of the business, and about which data may be stored. The instances of data type represent a specialization of a THING, such as invoice, order, application form, receipt, customer, supplier, employee, etc.

- Property. A relevant characteristic of a DATA ENTITY that further describes what that data entity is in the context of the business, such as order number, item price, customer address, invoice date, etc.

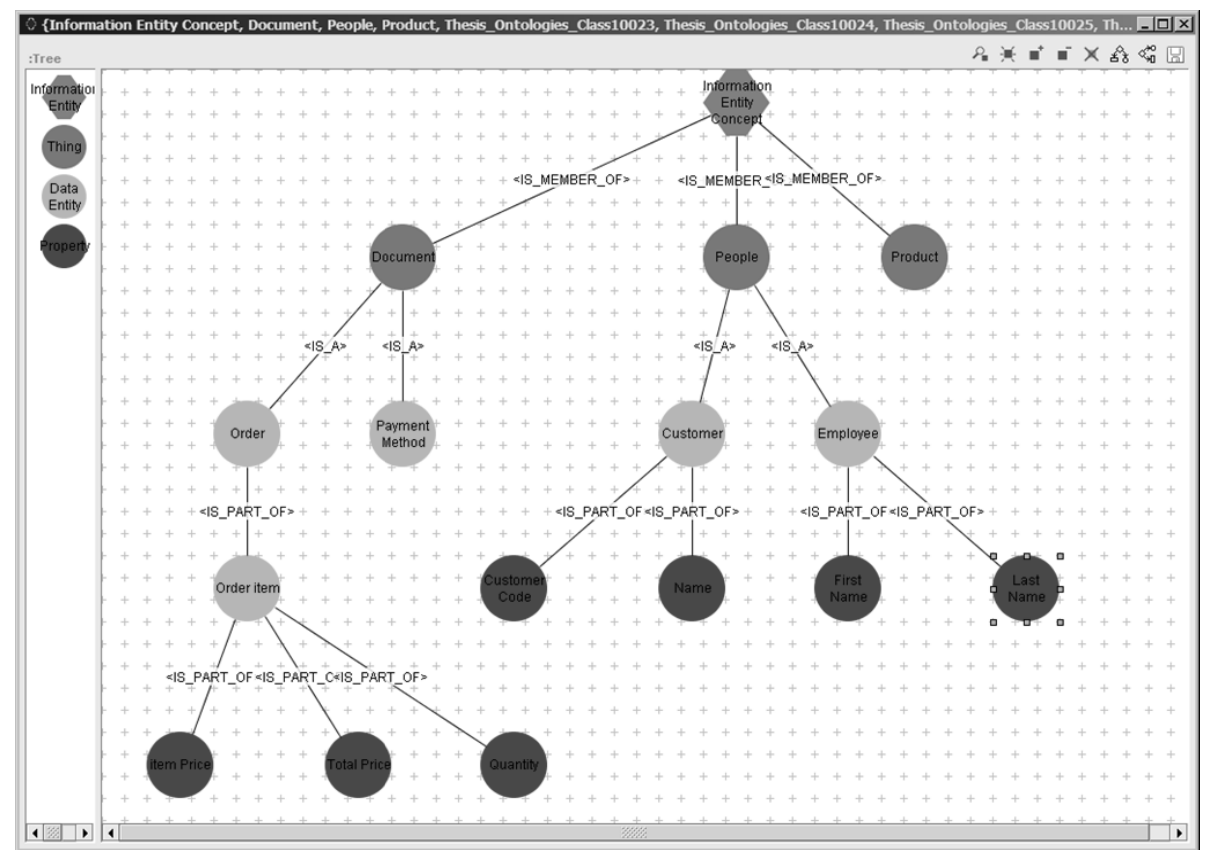

Fig. 3. Application of the ontology to an information entity

\subsection{Organizational Unit}

The organizational structure includes information about the ORGANIZATIONAL UNITS that make up an organization, the human resources that belong to those organizational units, as well as the structure and relationships that connect them all together. The three following concepts classify organizational unit: 
- GeOgRAPHiCAL LOCATION. Place where the organization is located which may be a country, city, geographical area, etc.

- Physical Location. Building where the organization is installed, e.g. headquarters, delegation, office, store, etc.

- UNIT. Used to create a hierarchy of organizational areas within a organization, e.g. division, department, section, etc.

\subsection{Actor}

Actor specifies a role played by a user or any other system that interacts with the subject. ACTORS may represent roles played by human users, information systems, or other active subjects. Note that an actor does not necessarily represent a specific physical entity but merely a particular role of some entity that is relevant to the specification of its associated use cases. Thus, a single physical instance may play the role of several different actors and, conversely, a given actor may be played by multiple different instances $[28,29]$. The concept of actor is classified as:

- Position. A function within a chain of command of an organization that has the responsibility for decisions involving the use of the organizational resources, i.e., manager, chief business officer, clerk, supervisor, project manager, etc.

\subsection{Business Schedule}

A BUSINESS SCHEDULE is a plan that specifies time periods for completing specific activities. In the context of this work, business schedule is the set of events that are important for the enterprise and have business process associated to them. A schedule is classified through events:

- Event. All occurrences happening at a determinable time that the organization must be aware of. Event can be decomposed as other events.

\subsection{Business Goal}

BUSINESS GOALS are a set of objectives that are accomplished by one more business process. Goals are classified as:

- GOAL. An end which the organization seeks to achieve through its operations.

- OBJECTIVE. A decomposition of GOAL that can be achieved within a defined timeframe and a set of resources.

- KPI. Key performance indicators can be associated to GOALS and OBJECTIVES to provide measures that will reflect success factors, such as time to answer a customer request or maximum lead time of a process.

\subsection{Relationships between the Taxonomy Concepts}

Table 1 summarizes the relationships between business processes and the remaining concepts. 
Table 1. Relationships between the core concepts and a business process

\begin{tabular}{|c|c|c|c|c|}
\hline \multicolumn{2}{|l|}{ Concept } & Macro-process & Process & Activity \\
\hline \multirow{3}{*}{ Information Entity } & Thing & $x$ & & \\
\hline & Data Entity & & $x$ & $x$ \\
\hline & Property & & & $x$ \\
\hline \multirow{3}{*}{ Organizational Unit } & Geographical location & $x$ & $x$ & \\
\hline & Physical location & $x$ & $x$ & \\
\hline & Unit & & $x$ & $x$ \\
\hline Actor & Position & $x$ & $x$ & $x$ \\
\hline Business Schedule & Event & $x$ & $x$ & $x$ \\
\hline \multirow{3}{*}{ Business Goal } & Goal & $x$ & & \\
\hline & Objective & & $x$ & $x$ \\
\hline & KPI & & & $x$ \\
\hline
\end{tabular}

\section{Conclusions}

The lack of a common language between the stakeholders and the process designers results in a significant gap between different modelling perspectives. To reduce this gap, this paper has proposed a controlled vocabulary to support business process design. This vocabulary is grounded on six dimensions of inquiry (how, where, why, when, what, who). The concepts pertaining to the vocabulary (information entity, business process, organizational unit, actor, business schedule and business goal) are organized as a taxonomy that allows for the hierarchical creation of an ontology that describes the specific domain of the organization. This approach has been experimented and validated in several professional projects at Link (www.link.pt).

Acknowledgments. The work described in this paper was co-supported with funding from the National Strategic Reference Framework - Quadro de Referência Estratégico Nacional, project QREN 6652.

\section{References}

1. Davenport, T., Short, J.: The New Industrial Engineering: Information Technology and Business Process Redesign. Sloan Management Review 32(5), 554-571 (1990)

2. Hammer, M., Champy, J.: Reengineering the Corporation: A Manifesto for Business Revolution. Nicholas Brealey Publishing, London (2001)

3. Dietz, J.: Enterprise Ontology: Theory and Methodology, p. 244. Springer, New York (2006)

4. van der Aalst, W.M.P., ter Hofstede, A.H.M., Weske, M.: Business Process Management: A Survey. In: van der Aalst, W.M.P., ter Hofstede, A.H.M., Weske, M. (eds.) BPM 2003. LNCS, vol. 2678, pp. 1-12. Springer, Heidelberg (2003)

5. OMG Business Process Model and Notation (BPMN), version 2.0 (2011) 
6. Ko, R., Lee, S., Lee, E.: Business process management standards: a survey. Business Process Management Journal 15(5) (2009)

7. Russell, N., van der Aalst, W.M.P., ter Hofstede, A.H.M., Edmond, D.: Workflow Resource Patterns: Identification, Representation and Tool Support. In: Pastor, Ó., Falcão e Cunha, J. (eds.) CAiSE 2005. LNCS, vol. 3520, pp. 216-232. Springer, Heidelberg (2005)

8. Dumas, M., Hofstede, A.H.t., Aalst, W.v.d.: Process Aware Information Systems: Bridging People and Software Through Process Technology. Wiley Publishing (2005)

9. Ellis, C.A., Nutt, G.J.: Workflow: The Process Spectrum. In: NSF Workshop on Workflow and Process Automation in Information Systems: State-of-the-Art and Future Directions, Athens, GA (1996)

10. IEEE Computer Society, IEEE Std 1471-2000: IEEE Recommended Practice for Architecture Description of Software-Intensive Systems. IEEE, New York (2000)

11. Davis, P., Tolk, A.: Observations on New Developments in Composability and MultiResolution Modeling. In: Winter Simulation Conference WSC 2007, Washington DC, USA (2007)

12. Malone, T.W., Crowston, K., Herman, G.A.: Organizing Business Knowledge: The MIT Process Handbook. MIT Press, Cambridge (2003)

13. Council, S.-C.: Supply Chain Operations Reference, SCOR (2003), http://supplychain.org/

14. Petri, C.A.: Kommunikation mit Automaten. In: Institut für instrumentelle Mathematik. University of Bonn, Bonn (1962)

15. Schriber, T.J.: Fundamentals of Flowcharting. Wiley, New York (1969)

16. Harel, D.: Statecharts: A visual formalism for complex systems. Sci. Comput. Program. 8(3), 231-274 (1987)

17. Keller, G., Nüttgens, M., Scheer, A.-W.: Ereignisgesteuerter Prozessketten (EPK). In: Semantische Prozessmodellierung auf der Grundlage, Saarbrücken, Germany (1992)

18. OMG, Unified Modeling Language Specification: Superstructure, version 2.0, Revised Final Adopted Specification (ptc/04-10-02). Object Management Group (2004)

19. OMG, Business Process Modeling Notation (BPMN) Specification. v 1.1 (formal/200801-17) (January 2008)

20. Chen, P.: The entity-relationship model: Towards a unified view of data. ACM Transactions on Database Systems 1(1) (1976)

21. Gane, C., Sarson, T.: Structured Systems Analysis: Tools and techniques. Prentice-Hall, Englewood Cliffs (1979)

22. Searle, J.: Speech Acts: An Essay in the Philosophy of Language. Cambridge University Press, Cambridge (1969)

23. Winograd, T.: A language/action perspective on the design of cooperative work. HumanComputer Interaction 3(1), 3-30 (1988)

24. Sousa, P., et al.: Applying the Zachman Framework Dimensions to Support Business Process Modeling. In: Digital Enterprise Technology Perspectives and Future Challenges 2007, pp. 359-366. Springer, US (2007)

25. Sousa, P., Lima, J., Sampaio, A., Pereira, C.: An Approach for Creating and Managing Enterprise Blueprints: A Case for IT Blueprints. In: Albani, A., Barjis, J., Dietz, J.L.G. (eds.) CIAO! 2009. LNBIP, vol. 34, pp. 70-84. Springer, Heidelberg (2009)

26. Krogstie, J., Sølvberg, A.: Information Systems Engineering - Conceptual Modeling in a Quality Perspective. Kompendiumforlaget, Trondheim (2003)

27. Spewak, S., Steven, H.: Enterprise Architecture Planning: Developing a Blueprint for Data, Applications and Technology. Wiley-QED Publication, New Jersey (1992) 
28. List, B., Korherr, B.: A UML 2 Profile for Business Process Modelling. In: Akoka, J., Liddle, S.W., Song, I.-Y., Bertolotto, M., Comyn-Wattiau, I., van den Heuvel, W.-J., Kolp, M., Trujillo, J., Kop, C., Mayr, H.C. (eds.) ER Workshops 2005. LNCS, vol. 3770, pp. 8596. Springer, Heidelberg (2005)

29. Caetano, A., Silva, A.R., Tribolet, J.: Business Process Model Decomposition with Separation of Concerns. In: 25th Annual ACM Symposium on Applied Computing, ACM SAC 2010. ACM, Sierre (2010) 